\title{
In vivo modulation of angiogenesis by beta 2 glycoprotein I
}

\author{
F.H. Passam ${ }^{\text {a,b }}$, J.C. Qi ${ }^{\text {a,b }}$, K. Tanaka ${ }^{\text {a,b }}$, K.I. Matthaei ${ }^{\text {c,d }}$, S.A. Krilis ${ }^{\text {a,b, * }}$ \\ a Department of Immunology, Allergy and Infectious Disease, University of New South Wales, St. George Hospital, 2 South St., Kogarah, NSW 2217, Sydney, Australia \\ ${ }^{\mathrm{b}}$ Department of Medicine, University of New South Wales, St. George Hospital, 2 South St., Kogarah, NSW 2217, Sydney, Australia \\ ${ }^{\text {c } S t e m ~ c e l l ~ a n d ~ G e n e ~ T a r g e t i n g ~ L a b o r a t o r y, ~ T h e ~ J o h n ~ C u r t i n ~ S c h o o l ~ o f ~ M e d i c a l ~ R e s e a r c h, ~ T h e ~ A u s t r a l i a n ~ N a t i o n a l ~ U n i v e r s i t y, ~ A C T, ~ C a n b e r r a, ~ A u s t r a l i a ~}$ \\ d Stem Cell Unit, Department of Anatomy, King Saud University, Riyadh, Saudi Arabia
}

Keywords:

Beta 2 glycoprotein I

Angiogenesis

Tumour development

\begin{abstract}
A B S T R A C T
Beta 2 glycoprotein I ( $\beta 2 \mathrm{GPI})$ is the major auto antigen in the antiphospholipid syndrome but also interacts with fibrinolytic and angiogenic proteins. The aim of this study was to examine the angiogenic potential of $\beta 2 \mathrm{GPI}$ in vivo in $\beta 2 \mathrm{GPI}$ deficient mice utilizing angiogenic assays. $\beta 2 \mathrm{GPI}$ deficient mice show increased microvessel formation in comparison to $\beta 2 \mathrm{GPI}$ replete controls when injected with growth factor free-matrigel implants. However, microvessel formation in matrigel plugs of $\beta 2 \mathrm{GPI}$ deficient mice was less than in $\beta 2$ GPI replete mice when basic fibroblast growth factor (bFGF) was included in the matrigel. Hemoglobin content was higher in vascular endothelial growth factor (VEGF) containingmatrigel plugs in the $\beta 2$ GPI deficient mouse demonstrating that the lack of $\beta 2 G P I$ led to increased extravasation by VEGF. Melanoma B16F10 tumour growth was enhanced in $\beta 2$ GPI deficient mice. Melanoma microvessel density was increased in $\beta 2$ GPI deficient mice but the proliferation rate of tumour cells (determined by Ki67 immunohistochemistry) was unaffected by the presence or absence of $\beta 2 \mathrm{GPI}$. Subcutaneous delivery of native human $\beta 2 \mathrm{GPI}$ by the ALZET osmotic pump did not affect melanoma tumour growth in $\beta 2 \mathrm{GPI}$ deficient mice. We conclude that the in vivo unopposed action of $\beta 2 \mathrm{GPI}$ is anti-angiogenic however this function is modified in the presence of a strong angiogenic stimulus into stabilization of vessel formation. Although the presence of $\beta 2$ GPI attenuates vessel sprouting in certain tumours, no survival benefit is conferred to tumour bearing animals. This does not preclude the potential benefit of modified or fragments of $\beta 2 \mathrm{GPI}$ in anti-angiogenesis research.
\end{abstract}

(c) 2010 Elsevier Ltd. All rights reserved.

\section{Introduction}

In adult life the formation of new vessels from pre-existing ones is a process termed angiogenesis. Excessive angiogenesis is a hallmark of multiple diseases such as inflammatory disorders and cancer and is caused by the dominance of pro-angiogenic over antiangiogenic regulators [1]. The onset of vessel sprouting is a discrete stage in tumour development known as "angiogenic switch" which depends on the type of tumour and its interaction with the microenvironment [2].

Over the last three decades there has been extensive research leading to the characterization of important pro-angiogenic factors, such as vascular endothelial growth factor (VEGF) [3] and basic fibroblast growth factor (bFGF) (also known as fibroblast growth

\footnotetext{
* Corresponding author at: Department of Immunology, Allergy and Infectious Disease, University of New South Wales, St. George Hospital, 2 South St., Kogarah, NSW 2217, Sydney, Australia. Tel.: +61 29113 2955; fax: +61 291133981.

E-mail address: s.krilis@unsw.edu.au (S.A. Krilis).
}

factor 2)[4] and the development of the first angiogenesis-targeted therapeutic agents. However, less is known about the production and function of naturally occurring anti-angiogenic molecules such as angiostatin [5]. Angiostatin is a product of the plasminogen/plasmin system and is a powerful inhibitor of angiogenesis. Plasmin in contrast promotes angiogenesis by enhancing pericellular proteolysis [6].

The plasma protein beta 2 glycoprotein I ( $\beta 2 \mathrm{GPI})$ has recently been ascribed anti-angiogenic properties in vitro and in vivo [7-10]. $\beta 2 \mathrm{GPI}$ is a single chain glycoprotein that consists of five repeating sequences (domains $\mathrm{I}-\mathrm{V}$ ) known as short consensus repeats, characteristic of the complement control protein superfamily [11]. The fifth domain (DV) differs from DI-IV in that it contains a lysinerich positively charged region which is critical for phospholipid binding [12] and an extra 20 amino acid tail which is mobile and projects from the main surface of $\beta 2 \mathrm{GPI}$. The $\beta 2 \mathrm{GPI}$ molecule is more widely known for being the major antigen in the antiphospholipid syndrome [13], an auto-immune disease characterized by thrombosis and recurrent miscarriages.

The function of $\beta 2 \mathrm{GPI}$ is unclear, however, it displays effects on multiple components of the coagulation and fibrinolytic system 
[14]. In particular, $\beta 2 \mathrm{GPI}$ interacts with both plasmin and angiostatin of the plasminogen/plasmin system $[10,15]$ with apparently opposing actions. Plasmin can proteolytically cleave $\beta 2$ GPI in the 20 amino acid tail of DV between $\mathrm{Lys}^{317}$ and $\mathrm{Thr}^{318}$ and produce "nicked" $\beta 2$ GPI. Nicked $\beta 2$ GPI binds to plasminogen and suppresses plasmin generation which represents an anti-angiogenic effect. However, nicked $\beta 2$ GPI was recently shown, by the same group, to bind angiostatin and attenuate its anti-angiogenic function [10]. In the current study we aimed to clarify the angiogenic potential of $\beta 2 \mathrm{GPI}$ in vivo and to assess the significance of $\beta 2 \mathrm{GPI}$ in tumour development. In order to address these aims, we performed a number of angiogenesis assays using genetically modified $\beta 2 \mathrm{GPI}$ null and wild type mice.

\section{Materials}

\subsection{Proteins-reagents}

Native $\beta 2$ GPI was purchased from Haematologic Technologies (Essex Junction, VT).

Recombinant human VEGF and recombinant human bFGF were purchased from R \& D Systems, Inc, (Minneapolis, MN). Growth factor reduced - phenol red free matrigel, zinc fixative and $40 \mu \mathrm{m}$ Mesh caps were from BD Biosciences (Bedford, MA). Freezing medium Tissue-Tek ${ }^{\circledR}$ OCT was from Ted Pella, Inc. (Redding, CA). Drabkin's reagent and bovine hemoglobin were from Sigma (St. Louis, MO). Heparin sodium was from Mayne Pharma Ltd. (Melbourne, Australia). Alzet osmotic pumps were purchased from Alzet Durect (Cupertino, CA).

\subsection{Antibodies and detection systems}

Rat anti-mouse CD31, rat IgG2a isotype control and the anti-Ig Rat Detection Kit were from BD Biosciences. Rabbit polyclonal antibodies to VEGF receptor 2, mouse angiostatin and to beta-actin were purchased from Abcam (Cambridge, CB, UK). Monoclonal rat anti-mouse Ki67 (clone TEC-3) was from DAKO (Glostrup, Denmark). For immunohistochemistry, the Epitope Retrieval Solution $\mathrm{pH}$ 6.0, streptavidin-HRP and 3,3'-diaminobenzidine (DAB) were from Novacastra (Newcastle upon Tyne, U.K). Bond Wash Solution was from Vision BioSystems (Melbourne, Australia). The BOND X Automated Immunostainer was used with the BOND Intense $\mathrm{R}$ Detection System (Vision Biosystems, Melbourne, Australia). The terminal deoxyribonucleotidyl transferase-mediated deoxyuridine triphosphate nick end labeling (TUNEL) assay: Apoptosis Mebstain Kit was from Beckman Coulter, Inc. (Fullerton, CA).

For Western blots, detection of the primary antibody was performed with goat anti-rabbit-HRP from DAKO followed by ECL Plus Western blotting detection reagents (GE Healthcare, Chalfont St. Giles, UK). Chemiluminescent detection was measured with LAS3000 (FUJIFILM) and densitometry analysis was with Quantity One Software (Bio-Rad, Hercules, CA).

\subsection{Cell lines and culture media}

The B16F10 mouse melanoma cell line was purchased from the American Type Culture Collection (ATCC) (Manassas, VA). The mouse melanoma cell line causes a highly vascularized tumour when injected subcutaneously in C57BL/6 mice [16]. Dulbecco's Modified Eagle Medium (DMEM), Phosphate Buffered Saline and fetal calf serum (FCS) were from Invitrogen, (Carlsbad, CA).

\subsection{Mice}

129/Sv/C57BL/6 mixed background $\beta 2 \mathrm{GPI}(-/-)$ mice were previously generated in our laboratory [17]. The $\beta 2$ GPI $(-/-)$ mice display a normal phenotype but have a prolonged thrombin generation time compared to wild type $\beta 2 \mathrm{GPI}(+/+)$ mice. For the current experiments C57BL/6 $\beta 2 \mathrm{GPI}(-/-)$ mice were derived by back crossing of $129 / \mathrm{Sv} / \mathrm{C} 57 \mathrm{BL} / 6$ $\beta 2 \mathrm{GPI}(-/-)$ mice of mixed genetic background for 10 generations $(n=10)$ with C57BL/6 mice. Genotyping of the C57BL/6 $\beta 2 \mathrm{GPI}(-/-)$ strain was performed by PCR of genomic DNA from tail tip using primers as previously described [17].

\section{Methods}

Animal studies received the prior approval of the Animal Ethics Committee of the University of New South Wales. All mice were euthanized by $\mathrm{CO}_{2}$ asphyxiation. Immediately after euthanization, approximately $1 \mathrm{ml}$ of whole blood was collected by cardiac puncture and serum was separated. Sera from all mice were stored at $-80{ }^{\circ} \mathrm{C}$ until use.

\subsection{Matrigel assay}

\subsubsection{Microvessel density}

Matrigel implants were prepared according to previously described methods with modifications [18,19]. Matrigel was thawed overnight on ice. Heparin was preincubated with VEGF for $5 \mathrm{~min}$ at RT and then added to matrigel at a concentration of VEGF $200 \mathrm{ng} / \mathrm{ml}$ and of heparin 0.02 units $/ \mathrm{ml}$. Subsequently, $0.5 \mathrm{ml}$ of the matrigel alone or matrigel plus VEGF preparation was injected subcutaneously into the right and left ventral surface of the flanks of $11 \beta 2 \mathrm{GPI}(-/-)$ and $11 \beta 2 \mathrm{GPI}(+/+)$ control mice (age 6-8 weeks). A subset of 6 mice per group were injected with $0.5 \mathrm{ml}$ matrigel containing bFGF $100 \mathrm{ng} / \mathrm{ml}$ and heparin 40 units $/ \mathrm{ml}$. Mice were euthanized after 7 days and the matrigel implants were removed. One matrigel implant was used for the measurement of hemoglobin content (see below) and the other implant from the lateral side was placed in zinc fixative for $24 \mathrm{~h}$ and subsequently paraffin embedded. For the staining of microvessels, sections of the matrigel implants were dewaxed, incubated with 3\% hydrogen peroxide for $10 \mathrm{~min}$, washed with wash solution twice, blocked with $2 \%$ skim milk for $20 \mathrm{~min}$ and washed again. Monoclonal rat anti-mouse CD31 antibody was added at 1:50 dilution, $100 \mu \mathrm{l}$ per section, for $1 \mathrm{~h}$ at RT. The secondary anti-Ig Rat Detection Kit was used according to the manufacturer's instructions. As a positive control mouse colon and skin samples were also stained with CD31. Negative controls were incubated with IgG2a isotype control at the same concentration as the primary antibody - for $1 \mathrm{~h}$ at RT. The slides were counterstained with hematoxylin. Microvessel density (MVD) was assessed by image analysis capturing five random fields at $\times 20$ power field and subsequent enumeration of stained vessels was performed on the captured images [20]. Two independent observers blinded to the identity of the matrigel sample assessed the MVD and interobserver variability was $\leq 20 \%$. MVD is expressed as the average number of vessels per power field. The Images were obtained by Leica Image Analysis, DMLB.

Staining for VEGFR2 was performed using formalin fixed matrigel implants from growth factor free-matrigel and VEGF containing-matrigel plugs from $\beta 2 \mathrm{GPI}(-/-)$ and $\beta 2 \mathrm{GPI}(+/+)$ mice. An avidin biotin blocking step was performed prior to application of the primary $\mathrm{Ab}$ (dilution 1:800) followed by the secondary goat anti-rabbit biotinylated $A b$ (1:200), and subsequent visualisation with streptavidin-HRP and DAB as the substrate. 


\subsubsection{Hemoglobin content}

Matrigel impants, harvested as above, were stored at $-80^{\circ} \mathrm{C}$. Measurement of the hemoglobin content was performed according to the Drabkin's method [19]. Drabkin's reagent was diluted in $1 \mathrm{~L}$ of distilled water and $500 \mu \mathrm{l}$ of BRIJ-35 solution was added. Bovine hemoglobin was used as a standard. Matrigel samples were thawed on ice to liquefy and then centrifuged at $9000 \mathrm{~g}$ for $10 \mathrm{~min}$ at $4{ }^{\circ} \mathrm{C}$ through a $40 \mu \mathrm{m}$ mesh cap which retained any tissue fragments. $10 \mu \mathrm{l}$ of matrigel sample was added to the 96 well plate and mixed with $200 \mu \mathrm{l}$ of Drabkin's solution and incubated for $20 \mathrm{~min}$ at RT. Optical density was read at $540 \mathrm{~nm}$ and hemoglobin concentrations were plotted against the standard curve. Hemoglobin concentrations were expressed as $\mathrm{mg} / \mathrm{ml}$.

\subsection{Tumour assay}

\subsubsection{Melanoma B16F10}

Murine melanoma cells B16F10 where grown in DMEM FCS 10\% until subconfluence. Passages 3-5 were used for injecting mice aged 9-10 weeks. One million B16F10 cells in $0.5 \mathrm{ml}$ PBS were injected subcutaneously into the dorsal surface of one flank of 20 $\beta 2 \mathrm{GPI}(-\mid-)$ and age and sex matched $20 \beta 2 \mathrm{GPI}(+\mid+)$ (10 male and 10 female mice per group). Tumour development was monitored and measured with a caliber. The evaluation of tumour volume was based on the equation: volume $=a \times(b)^{2} \times 0.52$ where $\mathrm{a}$ is the longest and $b$ is the shortest dimension of the tumour [21]. For the first 10 mice from each group ( 5 male and 5 female) the end point was 21 days. However, once tumours reached 10 days, there was rapid proliferation (e.g. ulceration of tumour, bleeding from tumour) requiring some mice to be euthanized before the 21 day end point. Therefore, the end point for the second series of 10 mice from each group was shortened to 16 days. Measurements of tumour dimensions were performed on days 10,13,16 and the mice were euthanized on day 16 . Tumours were excised and weighed. After dissection with a scalpel, approximately half of the tumour was snap frozen in freezing medium by immersion in liquid nitrogen. The remaining tumour was fixed with $10 \%$ neutral buffered formalin for $24 \mathrm{~h}$ followed by paraffin embedding.

Frozen sections were used to detect microvessels by CD31 staining. Slides were cut and dried overnight at RT. They were fixed with $95 \%$ ethanol for $10 \mathrm{~min}$ at $-20{ }^{\circ} \mathrm{C}$. Staining for CD31 was performed as described above. Frozen sections of mouse colon and skin were used as positive controls. IgG2a isotype control was used as a negative control as above.

Formalin fixed sections were used to detect the proliferation marker Ki67. Paraffin embedded tissues were dewaxed and antigen retrieval was performed by applying the retrieval solution in a microwave for $4 \mathrm{~min}$. Slides were stained with anti-Ki67 antibody diluted 1:25 for $1 \mathrm{~h}$ at RT followed by the anti-Ig Rat Detection Kit used in the BOND X Automated Immunostainer. Slides were counterstained with hematoxylin, dehydrated through graded alcohols and mounted with coverslips. Mouse skin, small intestine and thymus samples were used as positive controls.

The TUNEL assay on frozen melanoma sections was performed according to the manufacturer's instructions. FITC-dUTP probed apoptotic cells are stained green [22] and the overlay on blue of DAPI-stained nuclei produced light blue for apoptotic areas. Arbitrary estimate of apoptotic surface compared to the total cell surface of the slide was assigned as a score of 1 for $\leq 30 \%$ of cells as a score of 2 for $>30 \%$ of cells.

\subsubsection{Delivery of $\beta 2$ GPI subcutaneously in B16F10 injected $\beta 2 G P I(-/-)$ mice}

It has been previously reported that subcutaneous delivery of human nicked $\beta 2$ GPI into mice can inhibit orthotopic prostate cancer growth [8]. However, as the majority of circulating $\beta 2 \mathrm{GPI}$ is in its intact form we used the intact form to test its effect on melanoma tumour growth in $\beta 2 \mathrm{GPI}(-\mid-)$ mice. Under isofluorane anesthesia, an Alzet pump was inserted subcutaneously (loading volume $200 \mu \mathrm{l}$ ) containing either $1 \mathrm{mg}$ native $\beta 2 \mathrm{GPI}$ in $200 \mu \mathrm{l}$ sterile water ( 3 mice, aged 10 weeks) or $200 \mu \mathrm{l}$ of normal saline ( 3 mice, aged 10 weeks) into the dorsal surface of the mice (outlet facing towards the posterior leg). After $12 \mathrm{~h}, 1 \times 10^{6}$ B16F10 cells (in $1 \mathrm{ml}$ of PBS) were injected subcutaneously approximately $1 \mathrm{~cm}$ from the pump's outlet. Tumour size was monitored and mice were euthanized on day 16.

\subsubsection{Serum levels of angiostatin}

Angiostatin is a negative regulator of angiogenesis derived from the degradation of plasminogen [6]. $\beta 2$ GPI is cleaved by plasmin to nicked $\beta 2$ GPI that can bind angiostatin [10]. We determined circulating levels of angiostatin in tumour bearing mice to assess the effect of the presence of $\beta 2 \mathrm{GPI}$ on angiostatin production and to examine if the levels of angiostatin were related to tumour size. Sera from melanoma bearing mice were thawed and $20 \mu$ diluted in PBS (1:4) was separated on SDS PAGE and transferred to a membrane. The membrane was probed with rabbit anti-angiostatin Ab followed by detection with goat anti-rabbit HRP Ab. Consequently, the membrane was stripped and probed for antibeta actin Ab. Densitometry analysis was performed and the levels of angiostatin were normalized for beta-actin.

\subsection{Statistics}

Results are expressed as mean $+\mathrm{SD}$. For the comparison of measurements between the $\beta 2 \mathrm{GPI}(-/-)$ and the $\beta 2 \mathrm{GPI}(+/+)$ groups the paired $T$ test was used. For time course of tumour volume, analysis was done by one way ANOVA. Difference were significant when $p<0.05$.

\section{Results}

4.1. $\beta 2 G P I(-/-)$ mice exhibited increased MVD in growth factor free-matrigel implants compared to $\beta 2 \mathrm{GPI}(+/+)$ mice

The pattern of microvessel formation was different for each category of matrigel preparation. Injections with matrigel alone induced a cellular and vascular reaction of predominantly small and dense vessels in the adjacent subcutaneous tissue to the matrigel without cellular infiltration or vessel invasion of the matrigel matrix (Fig. 1A and B). Injection of VEGF containing-matrigel induced the formation of large dilated vessels and a cellular infiltrate which penetrated the matrigel matrix. Vessels could also be seen entering the matrigel matrix (Fig. $1 \mathrm{C}$ and D). Injection of bFGF containingmatrigel resulted in increased number of vessels with large blood lakes forming inside the matrigel plug (Fig. 1E and F).

The group of $\beta 2 \mathrm{GPI}(-/-)$ mice injected with matrigel alone displayed significantly increased MVD compared to $\beta 2 \mathrm{GPI}(+/+)$ controls ( $27 \pm 13$ versus $17 \pm 11$ (mean \pm SD) respectively, average number of microvessels per 10 power fields, $p<0.05, n=11$ ) (magnification $\times 20)$.

In contrast, $\beta 2 \mathrm{GPI}(-/-)$ mice injected with matrigel containing VEGF had a significantly lower MVD compared to $\beta 2$ GPI $(-/-)$ injected with matrigel alone $(p<0.01, n=11)$. The MVD was not statistically different when comparing the groups of $\beta 2 \mathrm{GPI}(-/-)$ with the $\beta 2 \mathrm{GPI}(+/+)$ mice injected with VEGF containing-matrigel $(13 \pm 8$ versus $18 \pm 12)$.

Moreover, $\beta 2 \mathrm{GPI}(-\mid-)$ mice injected with matrigel containing bFGF had a significantly lower MVD compared to $\beta 2$ GPI $(+/+)$ 


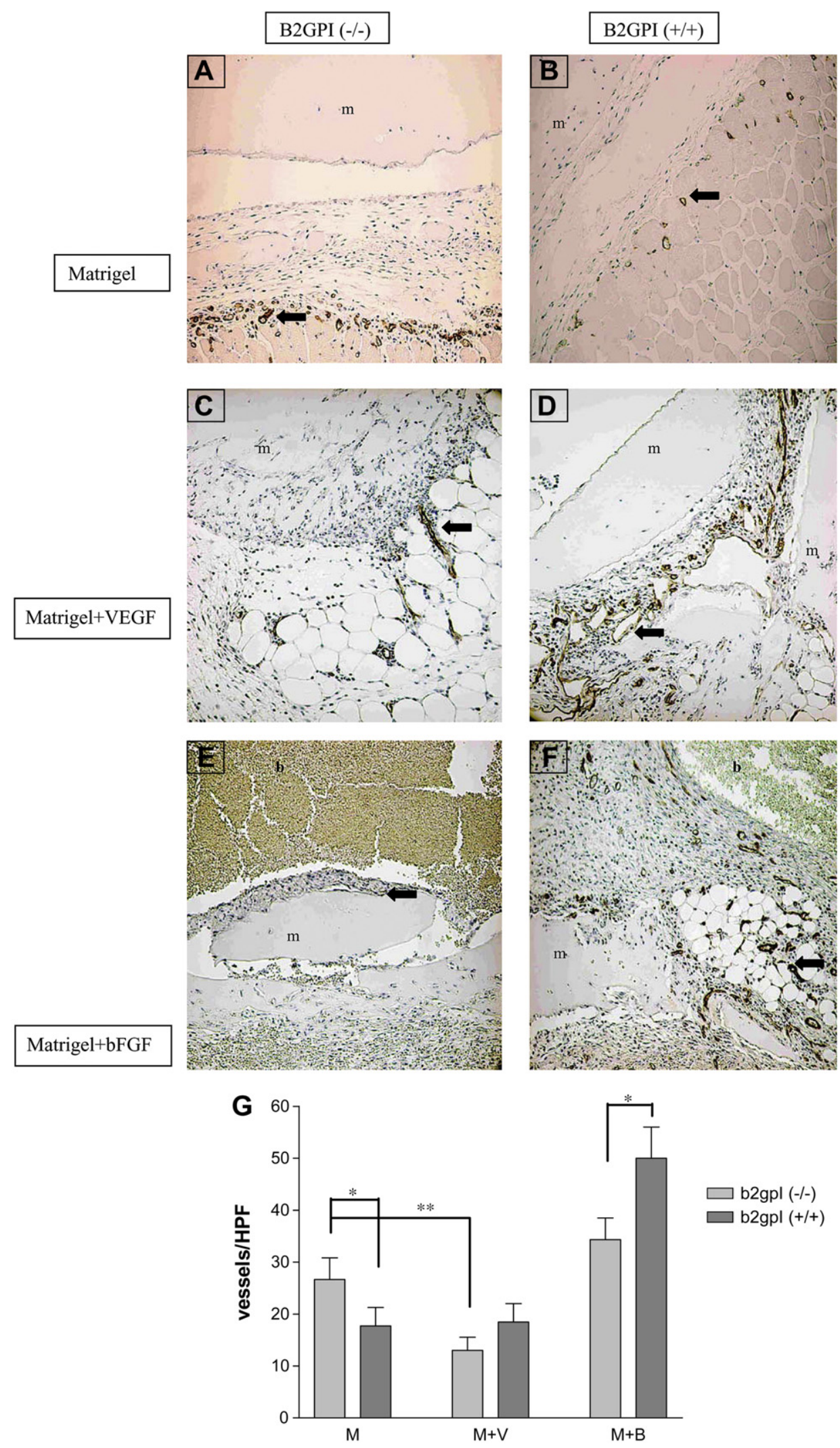

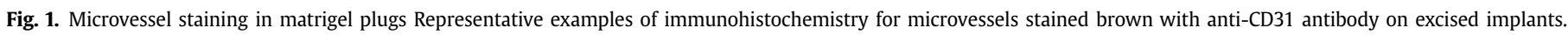

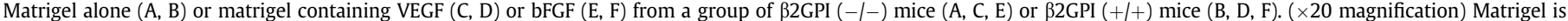

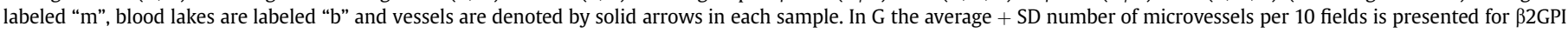
$(-/-)$ or $\beta 2 \mathrm{GPI}(+/+)$ injected with matrigel alone $(\mathrm{M})$, matrigel containing VEGF $(\mathrm{M}+\mathrm{V})$ and matrigel containing bFGF $(\mathrm{M}+\mathrm{B}) .{ }^{*} p<0.05,{ }^{* *} p<0.01$. 
group ( $34 \pm 10$ versus $50 \pm 14, p<0.05, n=6$ ). The data of MVD enumeration for all matrigel preparations are presented in Fig. 1G.

VEGFR2 staining was positive on endothelial cells in matrigels $( \pm$ VEGF) in both $\beta 2$ GPI $(-/-)$ and $\beta 2$ GPI $(+/+)$ mice ( 2 mice per group).

\section{2. $\beta 2 G P I(-/-)$ mice had increased hemoglobin content in VEGF} containing-matrigel plugs compared to $\beta 2 G P I(+/+)$ mice

The hemoglobin concentration in matrigel plugs has been used as a complementary measurement for the assessment of angiogenesis (see e.g. [23]). Growth factor free-matrigel plugs were macroscopically pale and translucent in both groups of $\beta 2 \mathrm{GPI}(-1-)$ and $\beta 2 \mathrm{GPI}(+/+)$ mice. Hemoglobin content was low and did not differ statistically between groups $(4.0 \pm 1.1 \mathrm{mg} / \mathrm{ml}$ for $\beta 2 \mathrm{GPI}(-/-)$ and $2.8 \pm 0.7 \mathrm{mg} / \mathrm{ml}$ for $\beta 2 \mathrm{GPI}(+/+)$, (mean $\pm \mathrm{SD}$ ), $n=11$ ) (Fig. $2 \mathrm{~A}$ and $2 \mathrm{E}$ ). This confirmed the histological pattern seen on microscopy of vascular development in the tissue adjacent to the matrigel and not in the matrigel itself for growth factor free-matrigel implants.

On the other hand, hemoglobin content was higher in VEGF containing-matrigels in the $\beta 2 \mathrm{GPI}(-/-)$ group in comparison with the $\beta 2 \mathrm{GPI}(+/+)$ group $(10.5 \pm 3.4$ versus $4.0 \pm 1.4 \mathrm{mg} / \mathrm{ml}$ respectively, (mean $\pm \mathrm{SD}$ ), $p<0.05, n=11$ ) (Fig. 2B, C, E).

The average hemoglobin content in bFGF-containing-matrigels was not different between $\beta 2 \mathrm{GPI}(-/-)$ group and $\beta 2 \mathrm{GPI}(+/+)$
$11.5 \pm 4.6$ versus $14.0 \pm 5.4 \mathrm{mg} / \mathrm{ml}$ respectively, (mean $\pm \mathrm{SD}$ ), $n=6$ ) (Fig. 2D and E).

4.3. $\beta 2 G P I(-/-)$ mice showed enhanced tumour development after injection with B16F10 melanoma cells compared to $\beta 2 \mathrm{GPI}(+/+)$ mice

The course of tumour development after subcutaneous injection of B16F10 cells showed a latent stage followed by a rapid development around day 10 onwards. Growth kinetics were evaluated in the subgroup of mice with end point at day 16. $\beta 2 \mathrm{GPI}(-/-)$ mice showed development of increased volume of tumours compared to $\beta 2 \mathrm{GPI}(+/+)$ mice at days 13 and 16 (Fig. 3A). The final net weights of the tumours were higher in the $\beta 2 \mathrm{GPI}(-/-)$ group compared to the $\beta 2$ GPI $(+/+)$ (Fig. 3B and C). A significant variation in final tumour weight was noticed among mice of the same group although they were of the same age.

\section{4. $\beta 2 G P I(-/-)$ mice displayed increased MVD of B16F10 melanoma tumours compared to $\beta 2 \mathrm{GPI}(+/+)$ mice}

Enumeration of microvessels on sections of frozen tissues showed that $\beta 2$ GPI $(-/-)$ mice as a group showed a significant increase in tumour MVD. A representative example is shown in Fig. 4A, B and the average number of microvessels is shown in Fig. 4C.
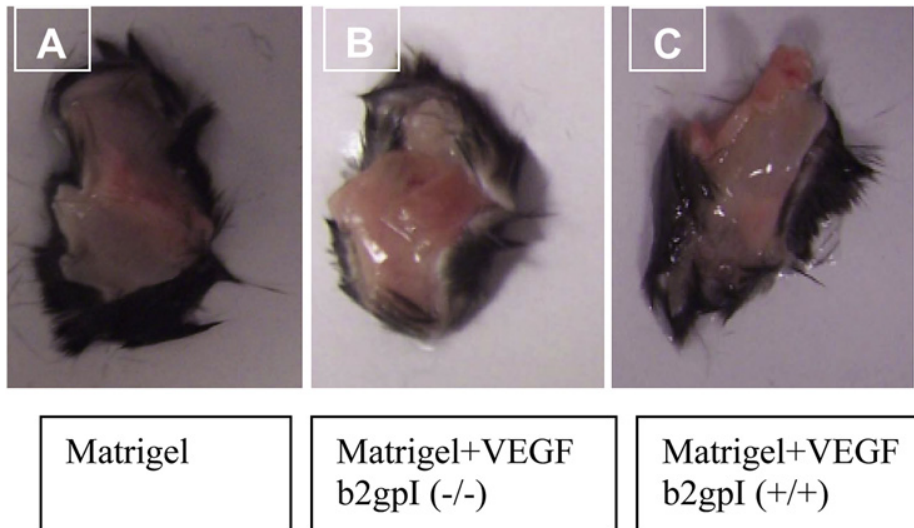

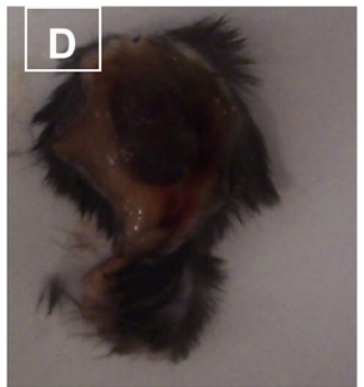

Matrigel+bFGF

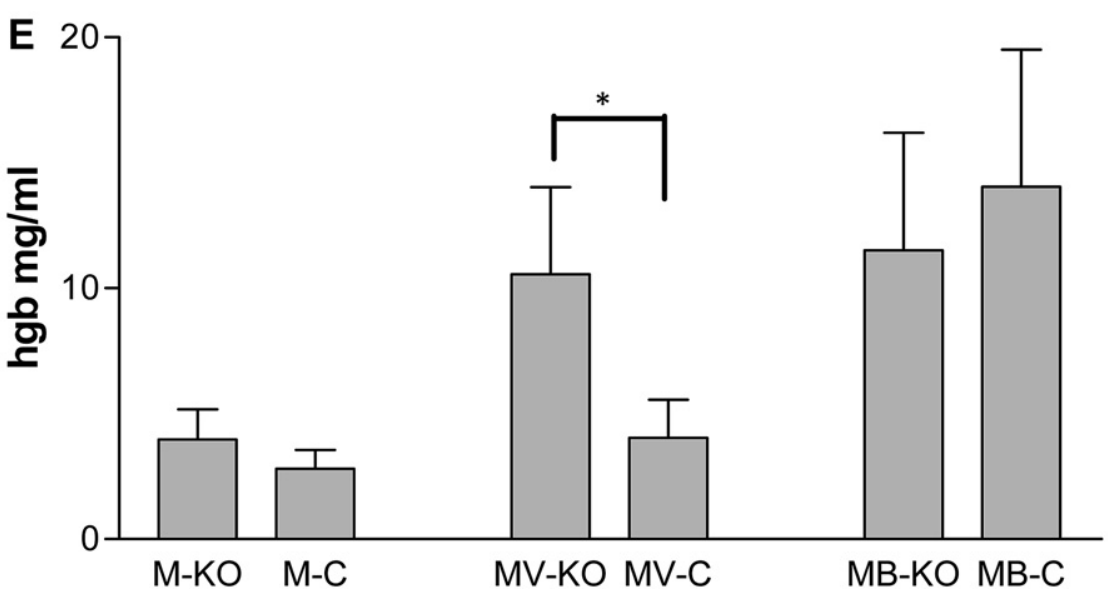

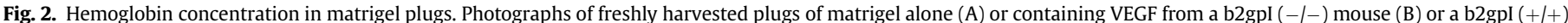

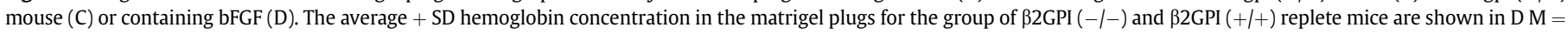
matrigel, $\mathrm{MV}=$ matrigel containing VEGF, $\mathrm{BV}=$ matrigel containing bFGF, $\mathrm{KO}=$ knockout mice b2gpI $(-/-), \mathrm{C}=\operatorname{control}$ mice b2gpI $(+/+),{ }^{*} p<0.05$. 

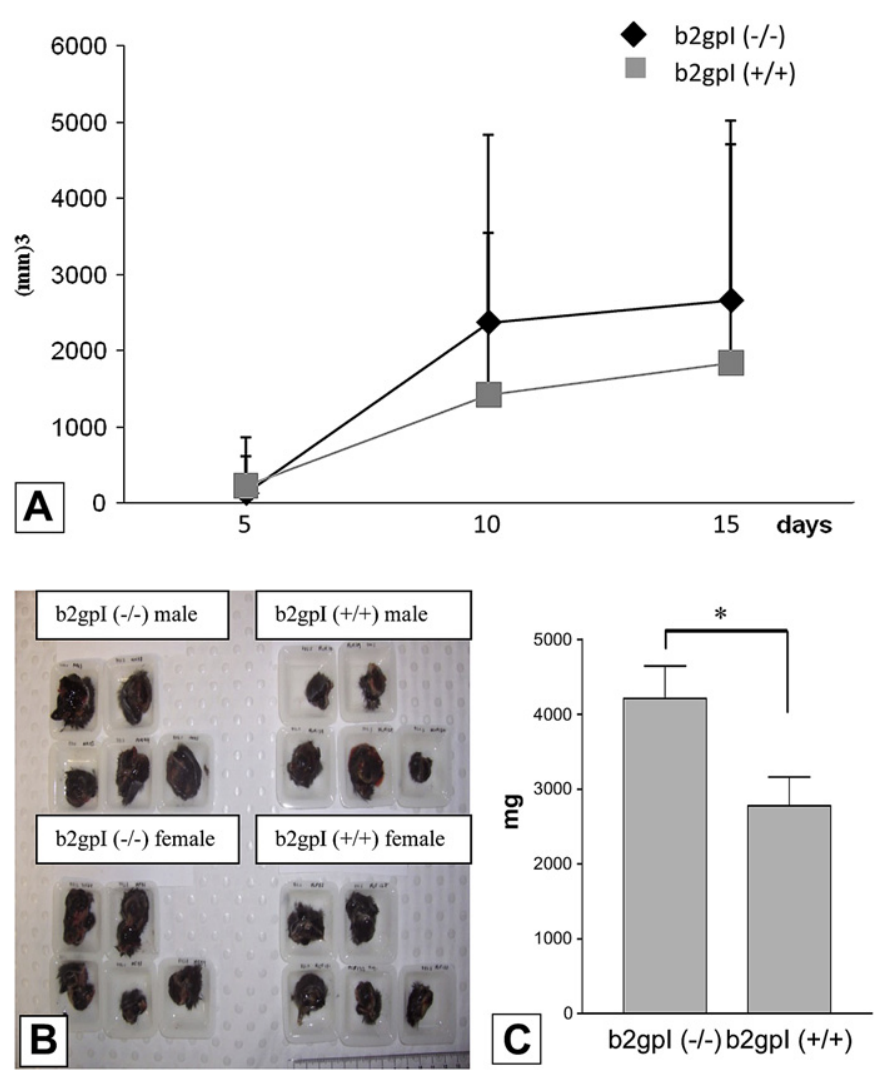

Fig. 3. Melanoma growth in $\beta 2$ GPI deficient and replete mice A. Tumour volume of B16F10 melanoma cells in $\beta 2 \mathrm{GPI}(-\mid-)$ and $\beta 2 \mathrm{GPI}(+\mid+)$ mice as a function of time. $\mathrm{B}$. Photograph of tumours resected after 16 days. $C$. The average + SD tumour weight in $\beta 2 \mathrm{GPI}(-/-)$ and $\beta 2 \mathrm{GPI}(+/+)$ mice. ${ }^{*} p<0.05$.

The proliferation marker Ki67 showed that there was a high proliferation rate for melanoma cells but that there was no difference when comparing the groups of $\beta 2 \mathrm{GPI}(-\mid-)$ mice with the $\beta 2$ GPI $(+/+)$ mice (Ki67 positive melanoma cells $79 \pm 7 \%$ versus $84 \pm 3 \%$ respectively (mean $\pm \mathrm{SD}$ ), $n=10$ ). $\beta 2 \mathrm{GPI}(-/-)$ mice appeared to have larger apoptotic areas compared to $\beta 2 \mathrm{GPI}(+/+)$ mice. $80 \%$ of $\beta 2 \mathrm{GPI}(-\mid-)$ received an apoptotic score of 2 compared to $40 \%$ of $\beta 2 \mathrm{GPI}(+/+)$ mice. However, statistically this difference did not reach significance $(p=0.052, n=10)$.

\subsection{Delivery of $\beta 2 G P I$ subcutaneously did not inhibit melanoma growth in $\beta 2 G P I(-/-)$ mice}

The final tumour weight in $\beta 2$ GPI $(-/-)$ mice subcutaneously administered human native $\beta 2 \mathrm{GPI}$ by a continuous osmotic pump was not statistically different from $\beta 2 \mathrm{GPI}(-/-)$ mice administered normal saline (3059 \pm 2444 versus $1819 \pm 749 \mathrm{mg}$ respectively (mean $\pm \mathrm{SD}), n=3$ ).

\subsection{Serum angiostatin levels did not depend on the presence} of $\beta 2 G P I$ or tumour size in B16F10 melanoma bearing mice

Densitometry of the angiostatin bands on the Western blots of sera from B16F10 injected $\beta 2 \mathrm{GPI}(-/-)$ and $\beta 2 \mathrm{GPI}(+/+)$ mice showed that there were no significant differences between the two groups. The intensity of the angiostatin bands was $56 \pm 25$ units/ beta-actin for the $\beta 2 \mathrm{GPI}(-\mid-)$ group (mean $\pm \mathrm{SD}), n=19)$ and $53 \pm 30$ units/beta-actin for the $\beta 2 \mathrm{GPI}(+/+)$ group (mean $\pm \mathrm{SD}$ ), $n=18$ ). There was no correlation of serum angiostatin levels with tumour size in either group of mice. Interestingly, higher molecular weight complexes detected by the anti-angiostatin $\mathrm{Ab}$ were detected only in the $\beta 2 \mathrm{GPI}(-/-$ ) group of mice (Fig. 5).

\section{Discussion}

The first demonstration of $\beta 2 \mathrm{GPI}$ as a negative regulator of angiogenesis in cancer came from Beecken et al. who isolated intact $\beta 2$ GPI as a fraction of transitional carcinoma cell media which caused distant tumour dormancy [7]. Using in vitro angiogenesis assays the same group demonstrated anti-angiogenic activity of plasmin treated $\beta 2 \mathrm{GPI}$ but not of intact $\beta 2 \mathrm{GPI}$. Our group has also shown that the in vitro anti-angiogenic effect of $\beta 2$ GPI could be mediated by both the intact and the plasmin nicked form [9]. The potential for therapeutic use of $\beta 2$ GPI was supported by Sakai et al. who demonstrated that delivery of nicked $\beta 2$ GPI subcutaneously could inhibit the growth of orthotopic prostate cancer in C57BL/6 mice [8]. Recently, a dual functionality of $\beta 2$ GPI as both a promoter and inhibitor of angiogenesis was proposed challenging its likely therapeutic potential [10]. From the published studies it seems that native $\beta 2 \mathrm{GPI}$ at high concentrations can inhibit angiogenesis with or without the presence of angiostatin whereas nicked $\beta 2 \mathrm{GPI}$ is anti-angiogenic in the absence of angiostatin.

How then is the anti-angiogenic effect of $\beta 2$ GPI mediated? The first mechanism, supported by results from our laboratory, is the down regulation of the VEGF receptor 2 and the inhibition of VEGF and bFGF downstream signaling events by $\beta 2$ GPI [9]. The second mechanism is indirectly supported by the studies demonstrating nicked $\beta 2$ GPI inhibiting the generation of plasmin. How do these proposed mechanisms of action translate into the findings of the current study? In vivo when $\beta 2 \mathrm{GPI}$ is absent (knockout mice) increased vasculature develops on the matrigel surface. Matrigel is an extract from murine Engelbreth-Holm-Swarm tumours which contains multiple proteins from the basement-membrane matrix [24]. The production of plasmin triggered at the matrigel-subcutaneous tissue interface may have been left unopposed in the $\beta 2 \mathrm{GPI}$ deficient mice leading to increased vessel formation. A summary of described interactions of $\beta 2 \mathrm{GPI}$ with other angiogenic regulatory molecules is shown in Fig. 6.

There was no difference in vessel formation in $\beta 2$ GPI deficient compared to replete mice injected with VEGF containing-matrigels. One explanation for this may be that the weak anti-angiogenic effect of $\beta 2 G P I$ was neutralized in the presence of the strong angiogenic VEGF stimulus. Alternatively, down regulation of the VEGFR2 by $\beta 2 G P I$ allowed alternative pro-angiogenic stimuli to dominate. It must be kept in mind that VEGFR2 also stimulates vasodilation and vascular permeability [3]. The unopposed action of VEGFR2 stimulation may therefore account for the significantly higher hemoglobin content in matrigel samples of $\beta 2 G P I$ deficient mice compared to the $\beta 2 \mathrm{GPI}$ replete control mice.

To add further complexity, bFGF showed increased microvessel density in the $\beta 2 \mathrm{GPI}$ replete mice. bFGF containing-matrigel had a higher heparin concentration in comparison to VEGF matrigels. Heparin binds with high affinity to $\beta 2 \mathrm{GPI}[25]$ and could possibly be preventing it from displaying its antibFGF function. Overall the matrigel study confirms that the in vivo effect of $\beta 2 \mathrm{GPI}$ is subject to various regulatory pathways, providing different angiogenic responses. VEGF and bFGF both interact with the plasminogen/ plasmin system potentially influencing the production of nicked $\beta 2 \mathrm{GPI}$. VEGF and bFGF promote the urokinase-type plasminogen activator ( $\mathrm{u}-\mathrm{PA}$ )/plasmin cascade by upregulating the u-PA receptor [26]. This could potentially lead to the production of increased amounts of nicked $\beta 2 \mathrm{GPI}$.

It is not clear which form of $\beta 2 \mathrm{GPI}$ (intact or nicked) is relevant in angiogenesis during physiological and pathophysiological states. 

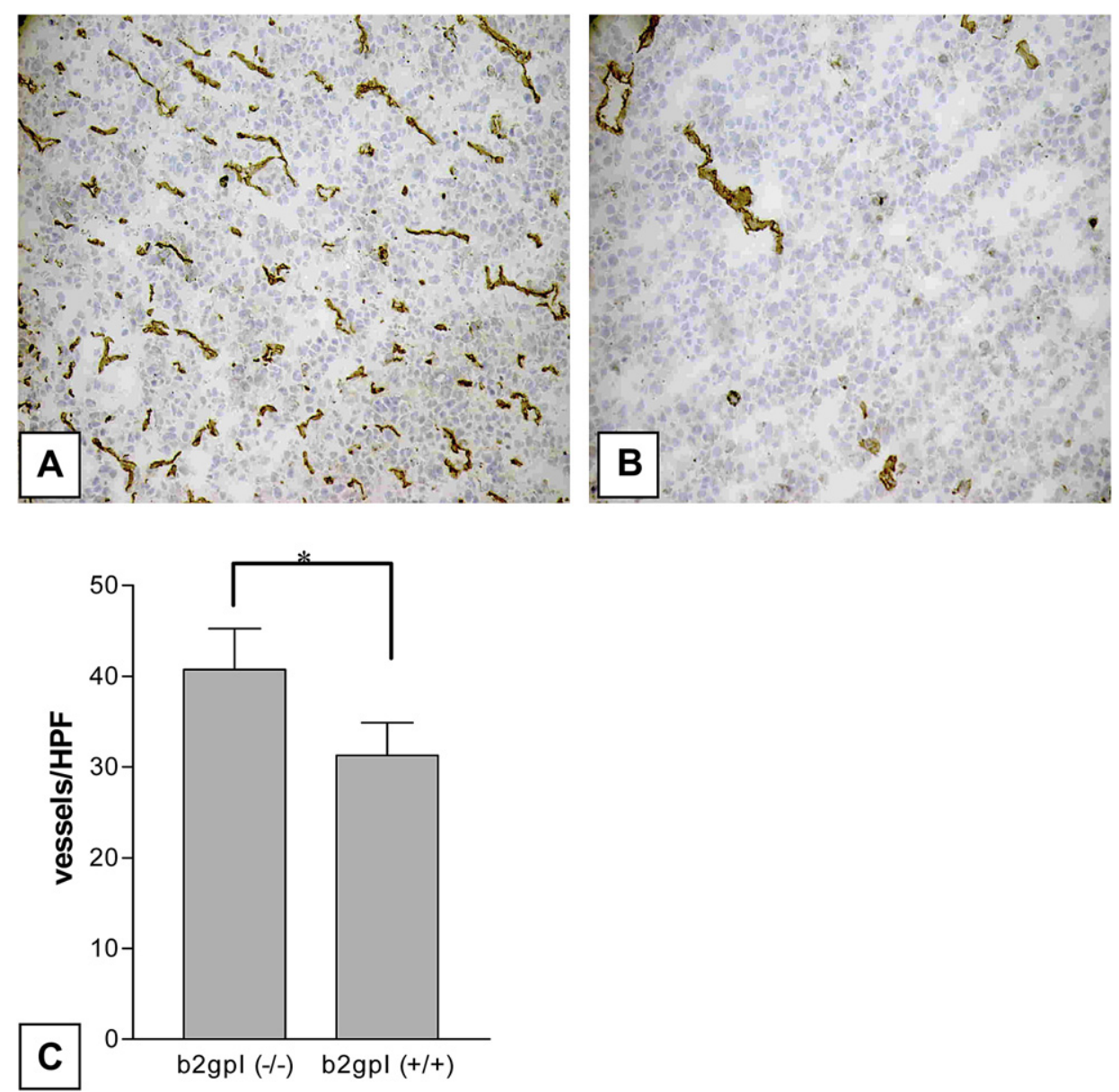

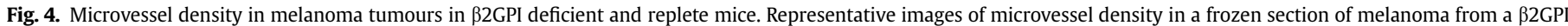
$(-/-)$ mouse $(\mathrm{A})$ and a $\beta 2 \mathrm{GPI}(+/+)$ mouse $(\mathrm{B})$. C. Average microvessel density $+\mathrm{SD}(n=20)$ for melanoma samples in $\beta 2 \mathrm{GPI}(-/-)$ and $\beta 2 \mathrm{GPI}(+/+)$ mice. ${ }^{*} p<0.05$.

This also applies to angiogenesis in the tumour setting. It was shown by Sakai et al. that nicked $\beta 2$ GPI could inhibit prostate cancer growth in C57BL/6 mice [8]. However the amount of nicked $\beta 2 \mathrm{GPI}$ administered to these mice ( $3.6 \mathrm{mg} / \mathrm{kg} / \mathrm{day}$ ) was supraphysiological and unlikely to be achieved in vivo. Circulating levels of nicked $\beta 2 \mathrm{GPI}$ in enhanced fibrinolytic states in humans reaches a maximum concentration of only $12 \mu \mathrm{g} / \mathrm{ml}$ [10]. Native human $\beta 2 \mathrm{GPI}$ did not influence melanoma growth in C57BL/6 mice. Although human and murine $\beta 2$ GPI display $76 \%$ amino acid sequence homology [17] the interspecies difference in $\beta 2$ GPI may have accounted for the lack of effect of human $\beta 2$ GPI in murine tumour development. Murine $\beta 2 \mathrm{GPI}$ in vivo displayed mild antiangiogenic properties as $\beta 2 \mathrm{GPI}$ deficient mice developed larger tumours with more vessels than $\beta 2 \mathrm{GPI}$ replete mice. The initial lag in tumour growth in $\beta 2 \mathrm{GPI}$ deficient mice was lost at later stages and mice succumbed regardless of $\beta 2 \mathrm{GPI}$ status. This has been shown previously with other angiogenic regulators such as angiopoietin 2 [27].

In tumour development the apoptotic rate is also an important determinant of outcome. Interestingly, apoptotic melanoma areas seemed more abundant in the $\beta 2$ GPI knockout mice. This is consistent with the protective effect of $\beta 2 \mathrm{GPI}$ on vascular cell apoptosis [28] or alternatively with an actual decrease in clearance of apoptotic cells in the knockout group as $\beta 2 \mathrm{GPI}$ enhances the clearance of apoptotic cells by macrophages [29]. Increased apoptosis in $\beta 2 \mathrm{GPI}$ deficient mice could be counterbalancing tumour growth as opposed to the increase in angiogenesis for the same group. We join the group of contributors in acknowledging the many contributions of Harry Moutsopoulos to rheumatology, to immunology, and to sufferers of Sjogren's syndrome and note that he is in very good company within this series that recognizes distinguished autoimmunologists [31-34].

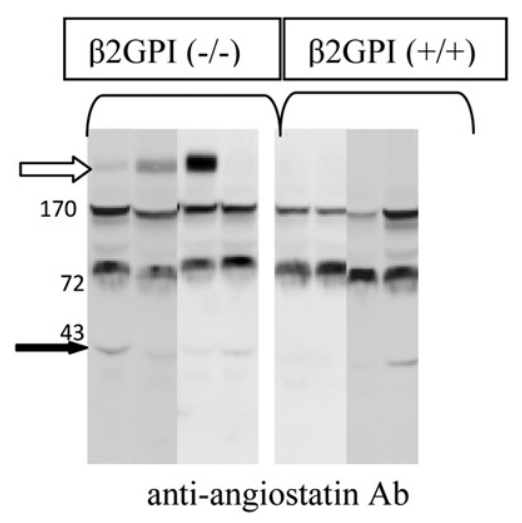

Fig. 5. Products of plasminogen degradation in serum of melanoma tumour bearing $\beta 2$ GPI deficient and replete mice Proteins from mice sera were separated on nonreducing SDS PAGE and probed with an antibody against kringle 3 domain of plasminogen. Angiostatin can be seen at MW $38 \mathrm{kD}$ whereas intact plasminogen is at $95 \mathrm{kD}$. The $\beta 2 \mathrm{GPI}(-/-)$ mice have a high MW complex, denoted with white arrow, which is not apparent in the $\beta 2 \mathrm{GPI}(+/+)$ mice. Representative of 4 sera for each group. 


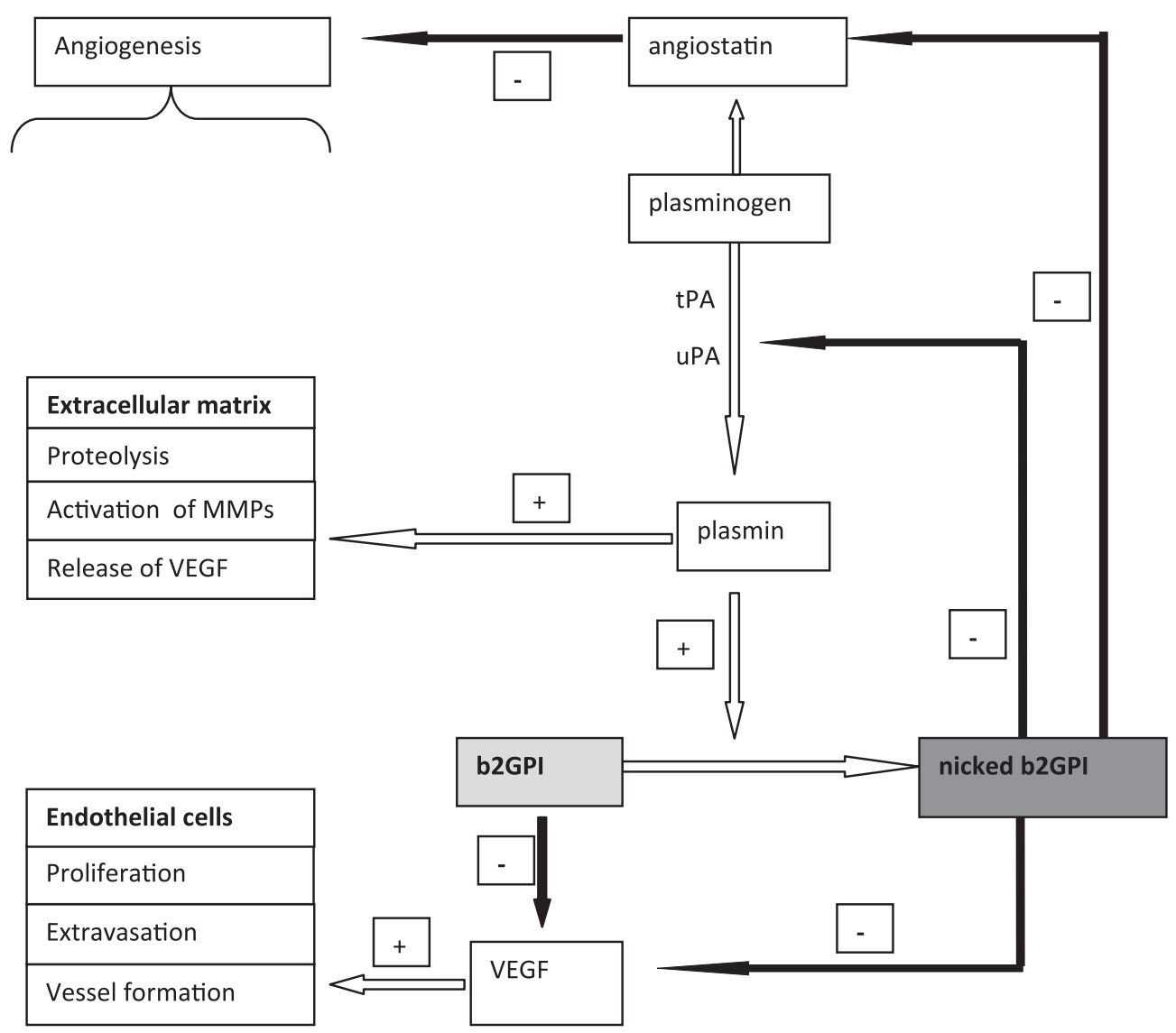

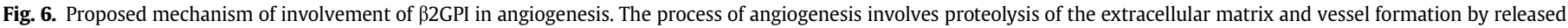

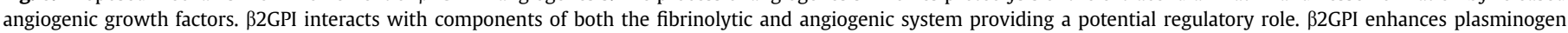

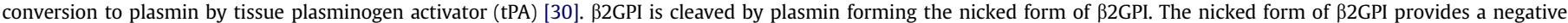

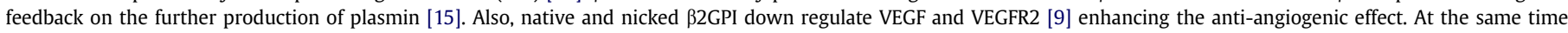

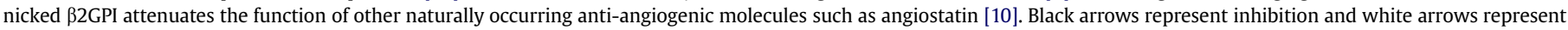
enhancement of the pathway.

\section{Conclusions}

1. $\beta 2$ GPI has weak anti-angiogenic activity which may be reversed in the presence of a strong angiogenic stimulus such as VEGF or bFGF.

2. $\beta 2 \mathrm{GPI}$ interacts with multiple regulators of the coagulation/ fibrinolysis and angiogenesis pathways and may confer both pro and anti-angiogenic effects.

3. In a tumour setting, the anti-angiogenic effect of $\beta 2$ GPI does not confer a survival benefit. This however does not exclude the possibility of modified or fragments of $\beta 2 \mathrm{GPI}$ exerting selective anti-angiogenic potential which may be exploited therapeutically.

\section{Disclosure of interest}

The authors declare no conflict of interest.

\section{Acknowledgments}

This work was supported by research grants from the Australian National Health and Medical Research Council (to S.A.K.), by a research grant from the Foundation of the Greek Society of Hematology (to F.H.P.)
The authors would like to acknowledge Gavin McKenzie from Histology of UNSW for the immunostaining of mouse tissues. We thank Vane (Wayne) Damcevski for expert technical support with the animal breeding.

\section{References}

[1] Carmeliet P. Angiogenesis in health and disease. Nat Med 2003;9:653-60.

[2] Bergers G, Benjamin LE. Tumorigenesis and the angiogenic switch. Nat Rev Cancer 2003;3:401-10.

[3] Ferrara N, Gerber HP, LeCouter J. The biology of VEGF and its receptors. Nat Med 2003;9:669-76.

[4] Presta M, Dell'Era P, Mitola S, Moroni E, Ronca R, Rusnati M. Fibroblast growth factor/fibroblast growth factor receptor system in angiogenesis. Cytokine Growth Factor Rev 2005;16:159-78.

[5] Dass CR, Tran TM, Choong PF. Angiogenesis inhibitors and the need for antiangiogenic therapeutics. J Dent Res 2007;86:927-36.

[6] Rakic JM, Maillard C, Jost M, Bajou K, Masson V, Devy L, et al. Role of plasminogen activator-plasmin system in tumor angiogenesis. Cell Mol Life Sci 2003;60:463-73.

[7] Beecken WD, Engl T, Ringel EM, Camphausen K, Michaelis M, Jonas D, et al. An endogenous inhibitor of angiogenesis derived from a transitional cell carcinoma: clipped beta2-glycoprotein-I. Ann Surg Oncol 2006;13:1241-51.

[8] Sakai T, Balasubramanian K, Maiti S, Halder JB, Schroit AJ. Plasmin-cleaved beta-2-glycoprotein 1 is an inhibitor of angiogenesis. Am J Pathol 2007;171: 1659-69.

[9] Yu P, Passam FH, Yu DM, Denyer G, Krilis SA. Beta2-glycoprotein I inhibits vascular endothelial growth factor and basic fibroblast growth factor induced angiogenesis through its amino terminal domain. J Thromb Haemost 2008;6: $1215-23$. 
[10] Nakagawa H, Yasuda S, Matsuura E, Kobayashi K, Ieko M, Kataoka H, et al. Nicked \{beta\}2-glycoprotein I binds angiostatin 4.5 (plasminogen kringle 1-5) and attenuates its anti-angiogenic property. Blood 2009;114:2553-9.

[11] Schwarzenbacher R, Zeth K, Diederichs K, Gries A, Kostner GM, Laggner P, et al. Crystal structure of human beta2-glycoprotein I: implications for phospholipid binding and the antiphospholipid syndrome. EMBO J 1999;18: 6228-39.

[12] Sheng Y, Sali A, Herzog H, Lahnstein J, Krilis SA. Site-directed mutagenesis of recombinant human beta 2-glycoprotein I identifies a cluster of lysine residues that are critical for phospholipid binding and anti-cardiolipin antibody activity. J Immunol 1996;157:3744-51.

[13] McNeil HP, Simpson RJ, Chesterman CN, Krilis SA. Anti-phospholipid antibodies are directed against a complex antigen that includes a lipid-binding inhibitor of coagulation: beta 2-glycoprotein I (apolipoprotein $\mathrm{H}$ ). Proc Natl Acad Sci USA 1990;87:4120-4.

[14] Miyakis S, Robertson S, Krilis S. Beta 2 glycoprotein I and its role in the antiphospholipid syndrome-lessons from knockout mice. Clin Immunol 2004;112:136-43.

[15] Yasuda S, Atsumi T, Ieko M, Matsuura E, Kobayashi K, Inagaki J, et al. Nicked beta2-glycoprotein I: a marker of cerebral infarct and a novel role in the negative feedback pathway of extrinsic fibrinolysis. Blood 2004;103:3766-72.

[16] Culp WD, Neal R, Massey R, Egevad L, Pisa P, Garland D. Proteomic analysis of tumor establishment and growth in the B16-F10 mouse melanoma model. J Proteome Res 2006;5:1332-43.

[17] Sheng Y, Reddel SW, Herzog H, Wang YX, Brighton T, France MP, et al. Impaired thrombin generation in beta 2-glycoprotein I null mice. J Biol Chem 2001;276:13817-21.

[18] Passaniti A, Taylor RM, Pili R, Guo Y, Long PV, Haney JA, et al. A simple, quantitative method for assessing angiogenesis and antiangiogenic agents using reconstituted basement membrane, heparin, and fibroblast growth factor. Lab Invest 1992;67:519-28.

[19] Min JK, Han KY, Kim EC, Kim YM, Lee SW, Kim OH, et al. Capsaicin inhibits in vitro and in vivo angiogenesis. Cancer Res 2004;64:644-51.

[20] Hansen S, Grabau DA, Rose C, Bak M, Sørensen FB. Angiogenesis in breast cancer: a comparative study of the observer variability of methods for determining microvessel density. Lab Invest 1998;78:1563-73.

[21] Zhang Z, Ramirez NE, Yankeelov TE, Li Z, Ford LE, Qi Y, et al. Alpha2beta1 integrin expression in the tumor microenvironment enhances tumor angiogenesis in a tumor cell-specific manner. Blood 2008;111:1980-8.
[22] Widera D, Mikenberg I, Elvers M, Kaltschmidt C, Kaltschmidt B. Tumor necrosis factor alpha triggers proliferation of adult neural stem cells via IKK/ NF-kappaB signaling. BMC Neurosci 2006;7:64.

[23] McMahon GA, Petitclerc E, Stefansson S, Smith E, Wong MK, Westrick RJ, et al Plasminogen activator inhibitor-1 regulates tumor growth and angiogenesis. J Biol Chem 2001;276:33964-8.

[24] Kleinman HK. Preparation of basement membrane components from EHS tumors. Curr Protoc Cell Biol; 2001 [Chapter 10:Unit 10.2].

[25] Guerin J, Sheng Y, Reddel S, Iverson GM, Chapman MG, Krilis SA. Heparin inhibits the binding of beta 2-glycoprotein I to phospholipids and promotes the plasmin-mediated inactivation of this blood protein. Elucidation of the consequences of the two biological events in patients with the anti-phospholipid syndrome. J Biol Chem 2002;277:2644-9.

[26] Kroon ME, Koolwijk P, Vermeer MA, van der Vecht B, van Hinsbergh VW. Vascular endothelial growth factor enhances the expression of urokinase receptor in human endothelial cells via protein kinase $C$ activation. Thromb Haemost 2001;85:296-302.

[27] Nasarre P, Thomas M, Kruse K, Helfrich I, Wolter V, Deppermann C, et al. Hostderived angiopoietin-2 affects early stages of tumor development and vesse maturation but is dispensable for later stages of tumor growth. Cancer Res 2009;69:1324-33.

[28] Lin KY, Wang HH, Lai ST, Pan JP, Chiang AN. beta(2)-glycoprotein I protects J774A.1 macrophages and human coronary artery smooth muscle cells against apoptosis. J Cell Biochem 2005;94:485-96.

[29] Maiti SN, Balasubramanian K, Ramoth JA, Schroit AJ. Beta-2-glycoprotein 1dependent macrophage uptake of apoptotic cells. Binding to lipoprotein receptor-related protein receptor family members. J Biol Chem 2008;283: 3761-6.

[30] Bu C, Gao L, Xie W, Zhang J, He Y, Cai G, et al. B2-Glycoprotein I is a cofactor of tissue plasminogen activator-mediated plasminogen activation. Arthrit Rheum 2009;60:559-68.

[31] Ansari AA, Gershwin ME. Navigating the passage between Charybdis and Scylla: recognizing the achievements of Noel Rose. J Autoimmun 2009;33 $165-9$.

[32] Whittingham S, Rowley MJ, Gershwin ME. A tribute to an outstanding immunologist - Ian Reay Mackay. J Autoimmun 2008;31:197-200.

[33] Gershwin ME. Bone marrow transplantation, refractory autoimmunity and the contributions of Susumu Ikehara. J Autoimmun 2008;30:105-7.

[34] Gershwin ME. The mosaic of autoimmunity. Autoimmun Rev 2008;7:161-3. 